\title{
CHARACTERISATION OF TRANSPORT RESILIENCE AND MEASURES TO ENHANCE RESILIENCE IN THE RECOVERY AFTER THE 2016 KAIKŌURA EARTHQUAKE
}

\author{
Dougal Mason $^{1}$ and Pathmanathan Brabhaharan²
}

(Submitted September 2020; Reviewed December 2020; Accepted March 2021)

\begin{abstract}
The Ward to Cheviot section of State Highway 1 is a key lifeline transport route that runs through the Kaikōura township. It is a strategically important link in the national state highway network, connecting the North Island via the Wellington-Picton ferry to the city of Christchurch in the South Island. Its strategic importance and vulnerable location between the mountainous Kaikōura range and the Pacific Ocean make it a critical transportation route in the national transport network. The route has been a focus for understanding the resilience of transport networks from as far back as 2000, when this section was used as a pilot study in early research into transport resilience. A further resilience assessment of this section was completed as part of a national state highway resilience study in mid-2016. Subsequently, the Mw 7.8 Kaikōura earthquake struck the northeast of the South Island on 14 November 2016, triggering thousands of large landslides and causing severe disruption to the transport network. The damage and disruption caused by the earthquake was comparable to that assessed in pre-earthquake studies of the resilience of the state highway. Landslides and embankment failures caused the most damage and disruption to the transport infrastructure, with the Main North Line railway closed for over 9 months and State Highway 1 closed for over a year. Post-earthquake landslides and debris flows triggered by storms caused additional damage and disruption during the recovery phase. Post-earthquake assessment of the corridor resilience was carried out to identify measures to enhance resilience as part of the recovery works. These measures included realigning the road and rail away from the steep hillsides, engineered works to reduce the potential for slope failure, and engineered works to reduce the potential for inundation of the corridor. The resilience assessments also enabled tactical and operational measures to be put in place to ensure safety while allowing the recovery operations to proceed in the context of enhanced risk associated with storm events and potential aftershocks.
\end{abstract}

\section{INTRODUCTION}

The resilience of our built environment to natural disasters such as earthquakes is critical for the community. New Zealand's rugged terrain and high seismicity over much of the country means that infrastructure, transport routes, residential developments etc. are prone to damage from natural hazards. Understanding the resilience of infrastructure to natural hazards including earthquakes is important to be able to take initiatives to enhance resilience.

Transport routes are critical lifelines for the community, particularly in the event of natural hazards. Research into the resilience of road networks in New Zealand led to the development of resilience principles and metrics to assess the resilience of road transportation routes on a more systematic and consistent basis [1,2]. This work included a pilot study to assess the resilience of the State Highway 1 corridor along the Kaikōura coast on the South Island of New Zealand. This study identified key vulnerabilities along the coastal Kaikōura route, where damage from natural hazard events such as earthquakes and large storms would result in loss of access at multiple locations along the route as well as lengthy recovery times. These vulnerabilities were reconfirmed in a resilience assessment of the national state highway network for the NZ Transport Agency (NZTA) in mid-2016 [3].

The magnitude 7.8 Kaikōura earthquake that struck on 14th November 2016 caused widespread damage across the northeast part of the South Island, including severe damage to the road and rail networks from fault rupture, strong ground shaking, and coseismic landslides. The Main North Line (MNL) rail corridor was closed for over 9 months and the coastal state highway corridor was closed for 13 months. The long outage of this nationally important corridor and long detours associated with the sole, distant, alternative route caused major disruption and highlight the need for prior planning to identify resilience gaps, to plan for event response, and to invest in strengthening key vulnerabilities. The availability of pre-earthquake resilience assessments of this corridor allowed comparison of actual damage with assessed vulnerabilities, as well as underpinning the post-earthquake assessment of the corridor resilience. Assessment of the postearthquake resilience was critical to the development of recovery and risk mitigation strategies that incorporated resilience benefits.

This paper presents the strategic importance of the route in the context of the resilience of the wider network, the impact and recovery operations from the Kaikōura earthquake, and a comparison of pre-earthquake resilience assessments with the observed damage and outage of the route. It also illustrates how ongoing resilience assessments following the earthquake were used to inform both recovery standards and facilitate construction work. 


\section{RESILIENCE OF THE REGIONAL TRANSPORT NETWORK}

\section{Strategic Importance}

The state highway network in the upper South Island is shown in Figure 1. The study area consists of a $150 \mathrm{~km}$ section of State Highway 1 (SH1) between Ward in Marlborough and Cheviot in north Canterbury. This section of the state highway passes through rolling hill country in Marlborough, along a narrow coastal strip to the north and south of Kaikōura, then through steep hill country between Oaro and Cheviot.

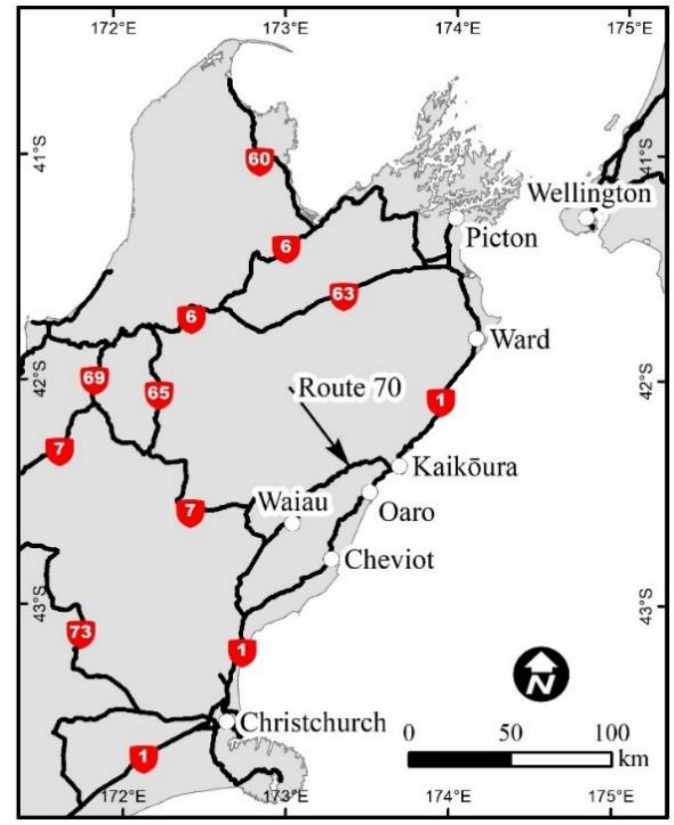

Figure 1: Map of the regional state highway network in the upper South Island.

The SH1 corridor is classified as a National Strategic HighVolume State Highway and a high productivity motor vehicle (HPMV) route. It is the primary freight route in the South Island, providing critical freight access between Christchurch and the North Island via Picton (Figure 1). This section of SH1 is also a key tourist route [4], providing access to tourist destinations such as Kaikōura, and there are important state highway connections with SH63, SH6 and SH7 that link SH1 with Nelson, Tasman and the West Coast.

\section{Natural Hazards and Incidents}

It is important to understand both the resilience of this critical SH1 route to natural hazards and its contribution to the resilience of the wider network. Previous studies of the SH1 corridor have assessed resilience impacts of large earthquakes and other high impact hazard events $[1,3,5]$ and route security and safety issues arising from more frequent hazard events $[4,6,7]$. These studies provide understanding of the distribution and magnitude of potential impacts from natural hazards, and consequently the resilience of the route in the context of the wider region.

Natural hazard events and vehicle crashes result in temporary road closures as well as longer term outages and consequential risks to route security. The predominant natural hazards in the region are storms and river/flood hazards, coastal erosion, landslides, earthquakes, tsunami, and sea level rise. Natural hazards occur in a range of intensities, from low intensity storms, small rock falls and landslides, or minor coastal erosion (all of which occur frequently with a high probability) to very high intensity events which occur with a low frequency or low probability such as large magnitude earthquakes, major storms or large tsunami. The impacts of these hazards on the transport system also vary. The combination of a narrow road corridor through steep terrain results in common slope instability, rock fall and slope movement impacts on the road. Frequent small events result in lane closures while the debris is removed and the pavement repaired, and occasional larger events can result in road closures. There are several major rivers crossing the route as well as low lying inland areas that are prone to flooding. Along the coastal section, streams draining from the ranges are prone to debris flows that can result in blocked culverts and flooding/debris inundation of the road. Coastal hazard impacts on the state highway infrastructure include undermining of the road foundation or loss of sealed surface and sediment blocking streams near the coast, leading to temporary road closures or lane closure while remediation works are carried out [4].

\section{Resilience Metrics}

The resilience of lifelines such as roads is the ability to minimise loss of service and readily recover and return to original form from adversity. Knowledge of the resilience of the road network in natural hazard events is important to understand the impact on society - the people, emergency services, economic activity etc. This also enables the estimated natural hazard resilience to be compared against desired level of service targets and to help develop resilience enhancement measures. The concept of resilience of lifelines is dependent on their vulnerability to a loss of quality or serviceability, and the time taken to bring them back into original usage state after a reduction or loss of access. This is shown conceptually in Figure 2, where following an adverse event there is a loss of service that requires a period of recovery time to restore the road or network back to its pre-event level of service. Thus, the smaller the shaded area, the more resilient is the service provided. The greater the area, the poorer is the resilience.

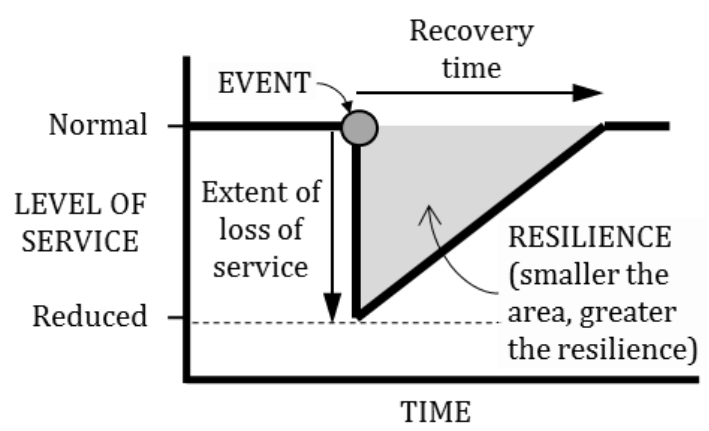

Figure 2: Resilience of infrastructure.

Brabhaharan et al. [2] define 'performance states' to assess the resilience of transport infrastructure. These metrics include the 'availability state', which defines the level of access after the event (representing the reduced level of service), and the 'outage state', which represents the duration of reduced access at a given availability state. These metrics of availability and outage states have been applied to assess the resilience of a number of transport networks [1,8-11].

\section{Route Resilience and the Wider Network Context}

Resilience is the ability to remain functional or quickly return to functionality and adapt when exposed to shock events or progressive events. A resilient transportation network requires its constituent routes to be robust with good redundancy and connectivity, to provide continued access to communities [12]. The transport network in the upper South Island is highly vulnerable to natural hazards, and critical sections are vulnerable to short to moderate closures in moderate hazard 


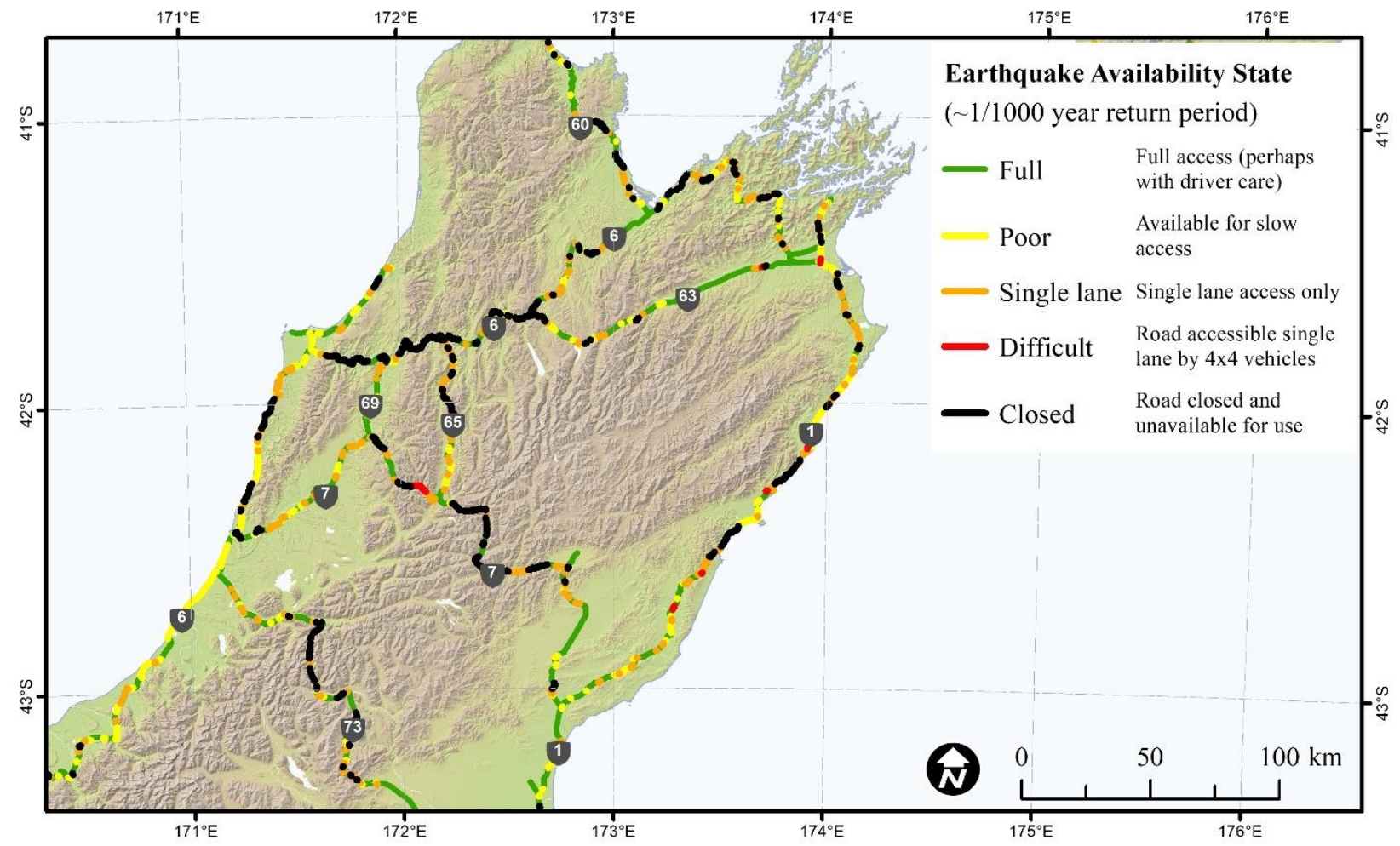

Figure 3: Earthquake availability state map of state highways in northern South Island [3].

events and major closures for many months in larger hazard events. This vulnerability was apparent from previous studies of route security and network resilience $[1,3,4,7]$, and was subsequently realised after the 2016 Kaikōura earthquake, when closure of the coastal section of SH1 resulted in traffic being forced to use the alternative inland route via SH63/SH6/SH65/SH7 (see Figure 1), adding $144 \mathrm{~km}$ to the journey $[13,14]$.

The resilience of the national state highway network to the impacts of a large earthquake were assessed in the 2016 national state highway resilience study for NZTA [3]. The availability state map for the regional state highway network in the upper South Island is shown in Figure 3. This shows that these alternative routes also cross steep mountainous terrain that is prone to damage and lengthy closures from natural hazards, indicating the vulnerability of the upper South Island transportation network. When a state highway corridor is closed, alternative detour routes are limited and lengthy, due to the remoteness and mountainous terrain of the upper South Island and lack of available local or rural roads. The resilience context of the coastal SH1 route is therefore characterised by high strategic importance, coupled with high vulnerability to hazards and poor network redundancy and connectivity, resulting in a high criticality for resilience on a regional and national level.

\section{KAIKŌURA EARTHQUAKE}

\section{Ground Shaking}

A severe magnitude 7.8 earthquake struck $15 \mathrm{~km}$ north-east of Culverden in the South Island of New Zealand, at 12:02 am on Monday 14th November 2016. This was followed by numerous aftershocks. At least 21 faults ruptured on and offshore of the north-east of the South Island of New Zealand (Figure 4). The ruptures began on The Humps Fault near Waiau and continued north-eastwards for $\sim 180 \mathrm{~km} \mathrm{[15].}$

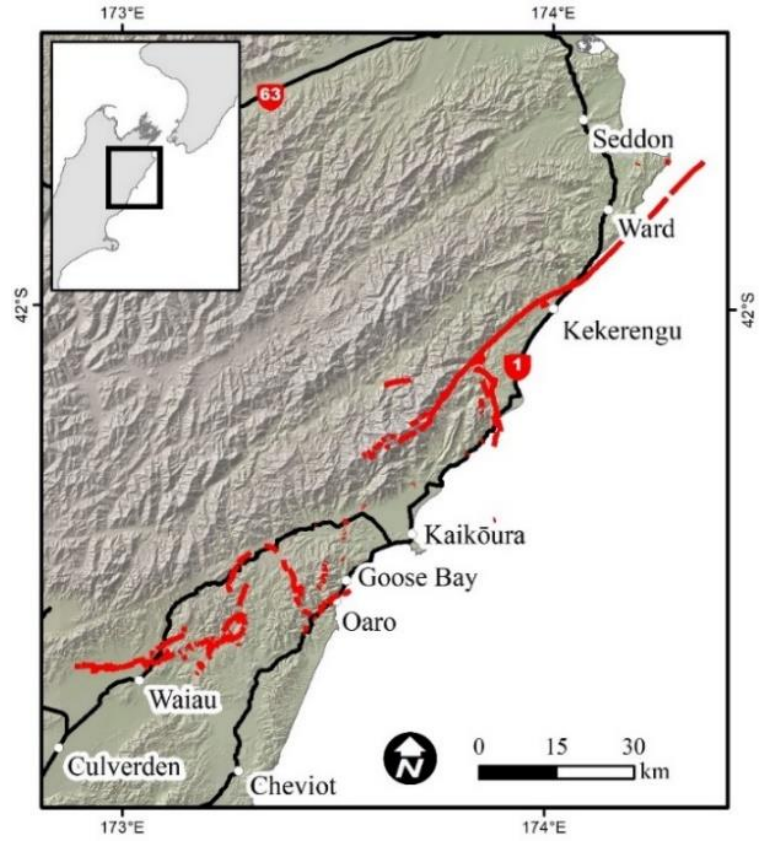

Figure 4: Fault ruptures in the Kaikoura earthquake, $14^{\text {th }}$ November 2016 [16].

Ground shaking was strongest in the epicentral region near Culverden, and to the northeast between Kekerengu and Seddon (Figure 5). The strong shaking near Ward is possibly due to the southwest-to-northeast earthquake rupture sequence directed towards this part of the South Island [17]. The ground shaking attenuated rapidly towards the south, with minimal shaking south of Amberley (57 km south of epicentre), but moderate shaking affected areas as far north as Wellington $(200 \mathrm{~km}$ northeast of the epicentre) across Cook Strait [18]. 

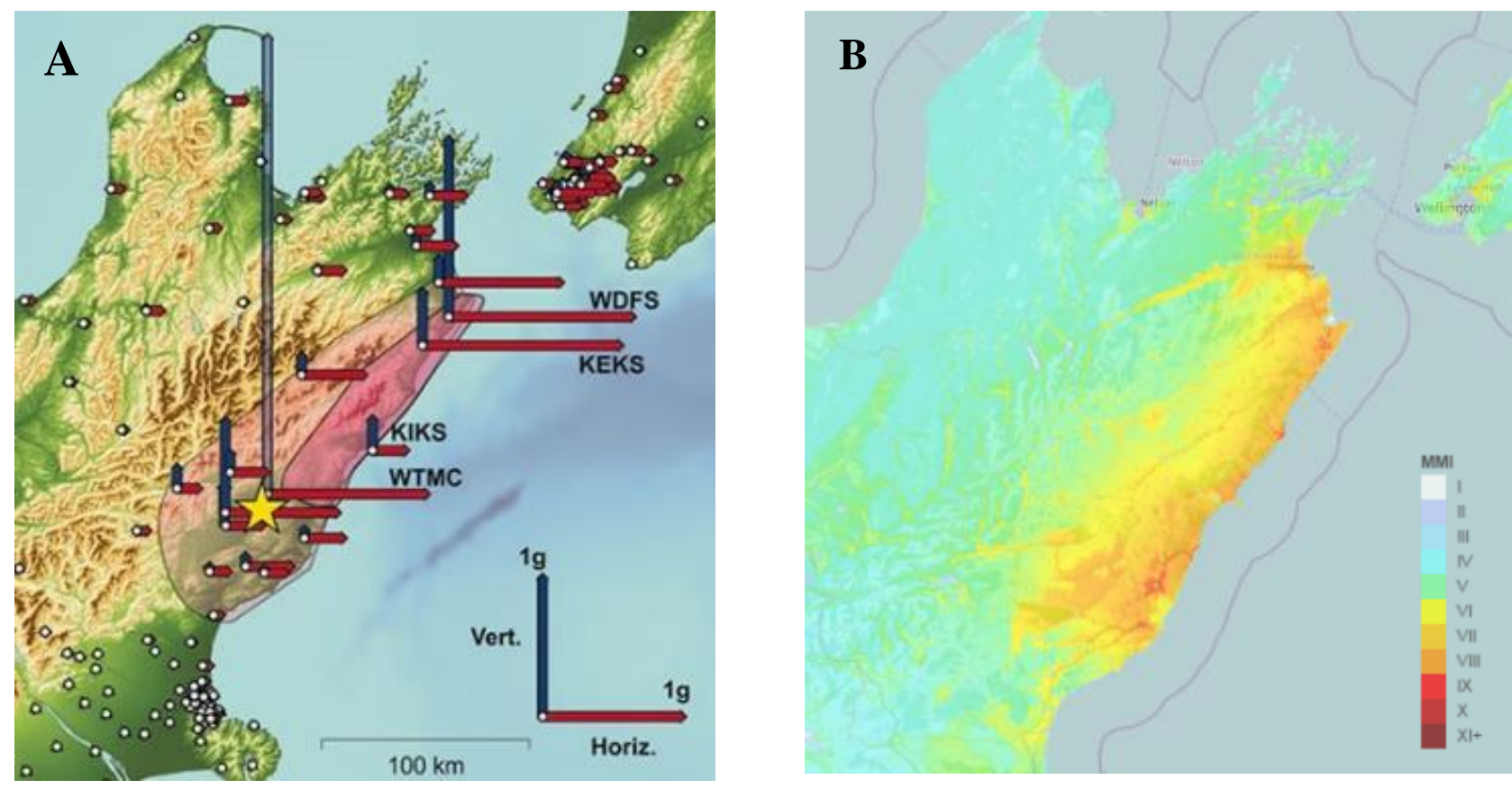

Figure 5: Ground shaking in the Kaikoura earthquake, $14^{\text {th }}$ November 2016. (A) Peak ground accelerations, with the extent of mapped landslides in the pink shaded areas [19]. (B) Modified Mercalli Intensity of shaking [20].

\section{Damage and Outage of Transport Infrastructure}

The earthquake caused widespread damage across the northeast of the South Island. In particular, fault rupture, strong ground shaking, and coseismic landslides severely damaged the road and rail networks, including SH1 and the MNL railway between Ward and Cheviot, and local roads in the Hurunui, Kaikōura and Marlborough districts. The damage extended over a nearly $200 \mathrm{~km}$ length along SH1 and the railway line. Landslides and embankment failures caused the most damage and disruption to the transport infrastructure in the earthquake [21]. The locations of mapped slope failures along the road and rail corridors are shown in Figure 6 [22]. Over 1500 sites were damaged along the road network, including 200 sites on SH1 between Clarence River and Cheviot that involved landslides and damage to bridges, road pavement, embankments, tunnels, culverts and road safety barriers and signage. Over 950 sites were damaged on the MNL, including tracks, slopes, embankments, tunnels, bridges, culverts and communications systems [23].

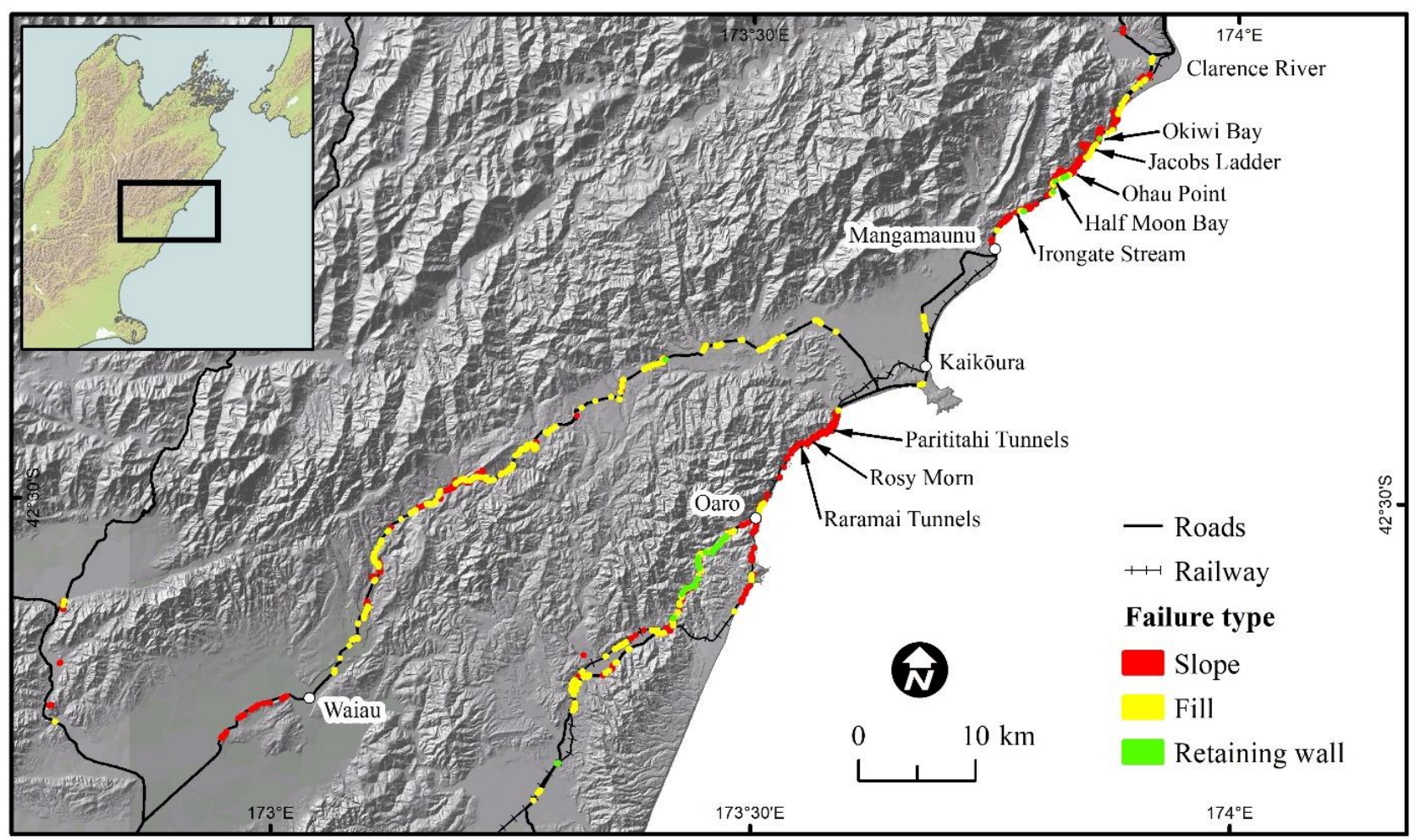

Figure 6: Locations of earthworks slope failures along the road and rail corridors in the Kaikōura earthquake. 

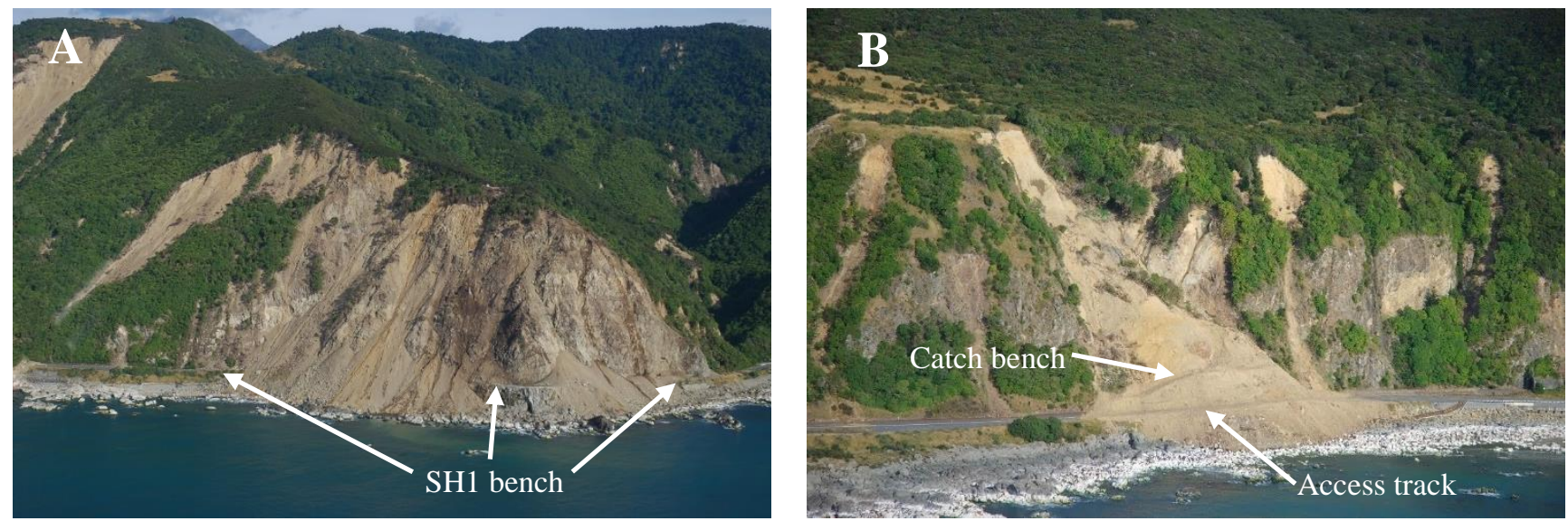

Figure 7: Examples of major landslides north of Kaikōura (see Figure 6 for locations). (A) Coalescing debris avalanches burying the SH1 road bench at Slip 'P6' at Ohau Point. The MNL rail line is situated in a tunnel through the hill. (B) Rock slide burying the road and rail corridors at Slip 'P8' in Okiwi Bay, with a 4 WD access track and temporary rock fall bench constructed across the toe of the slip debris.

NZ Transport Agency's contractors began to clear SH1 to Kaikōura from the south on 15 November 2016, and army convoys began travelling on Route 70 in the first few days after the earthquake to deliver essential supplies to Kaikōura. Blockage of access from failures of low height cut slopes and cracking/displacement of fill embankments were able to be repaired quickly to provide at least limited access, and only caused a short-term closure of the order of a few days. Landslides on higher cut slopes or natural hillslopes resulted in much longer outages due to the larger volumes of debris to clear as well as to manage the risks to earthmoving personnel and equipment from rock fall. By 18 November, SH1 was open between Blenheim and Ward, and there was controlled access along SH1 between Cheviot and Goose Bay. SH1 between Ward and Clarence was opened on 12 December, Route 70 reopened on 19 December, and SH1 south of Kaikōura reopened on 21 December for daytime operation only [13].

North of Kaikōura, the road and rail corridors were blocked by 10 major landslides on cuts and natural hillslopes extending $50 \mathrm{~m}$ to $100 \mathrm{~m}$ or more above the transport corridor (Figure 7A). These landslides were characterised by large volumes of debris and rock fall that completely buried the transport corridors. This resulted in prolonged closures due to the unstable nature of the debris, the presence of disrupted rock masses along the slopes and the safety risk posed by rock fall. These made reconstruction efforts more difficult, and involved a much longer duration for clearing of debris as it required sluicing, roped access scaling and careful formation of access tracks before debris could be cleared safely.

By March 2017, 4WD access tracks for construction plant had been built around the base of 8 of the 10 major slips (Figure 7B). The road corridor remained blocked by a major landslide at Ohau Point until August 2017, 9 months after the earthquake, when a construction access track was cleared around the base of the slip. The MNL reopened for freight trains in September 2017, and SH1 reopened for public access on 15 December 2017, during daylight hours only and with lengthy unsealed single lane sections, speed restrictions and stop-go traffic management. Construction work continued on the rail and road corridors after reopening, with 24-hour operation of the road recommencing in April 2018 and passenger trains resuming in December 2018.

\section{COMPARISON OF DAMAGE IN THE KAIKŌURA EARTHQUAKE WITH PRIOR RESILIENCE ASSESSMENTS}

The resilience of the coastal state highway corridor through Kaikōura to low frequency, high impact natural hazard events has been assessed and mapped by Brabhaharan et al. [1] and Mason and Brabhaharan [3], which was completed before the Kaikōura earthquake. The damage caused by the earthquake allowed comparison of the observed performance with that anticipated from these studies. This is illustrated in Figure 8, which shows the Availability State from the corridor-level study carried out in 2000-2001 and the observed performance in the 2016 earthquake. The observed performance was mapped using the observations during the post-earthquake response in November 2016 and post-earthquake LiDAR imagery and maps, captured using the same metrics as the resilience study [24].

\section{Loss of Route Availability}

The vulnerabilities identified in the 2001 resilience study as well as the 2016 national state highway resilience study were distinctively demonstrated in the Kaikōura earthquake, particularly the hazard posed by strong ground shaking and coseismic landslides. As seen in Figure 8, the observed availability of the state highway following the earthquake generally ties in with that assessed in the 2001 study. The route was closed over most of the coastal sections of the highway, predominantly due to inundation of the road platform by large volumes of landslide debris. However, not every section assessed as vulnerable to damage was closed in the earthquake event. The pre-earthquake studies assessed the level of damage and outage for a large magnitude earthquake (with a nominal return period of $\sim 1 / 1000$ years) that did not relate to a specific earthquake scenario such as rupture of a particular fault. Instead these studies assumed a consistent and high level of ground shaking along the whole study corridor. As a result, sections of steep hillslopes in close proximity to the road corridor were grouped together as being vulnerable to closure or reduction to single lane. Conversely, ground shaking in the Kaikoura earthquake varied considerably along the coastal corridor, depending on the local ground conditions, distance from the epicentre and fault ruptures, and topographic amplification and rupture directivity effects. Consequently, some sections identified as being vulnerable to closure in the 2001 study did not get damaged in the 2016 earthquake due to lower levels of ground shaking than assumed in the resilience 

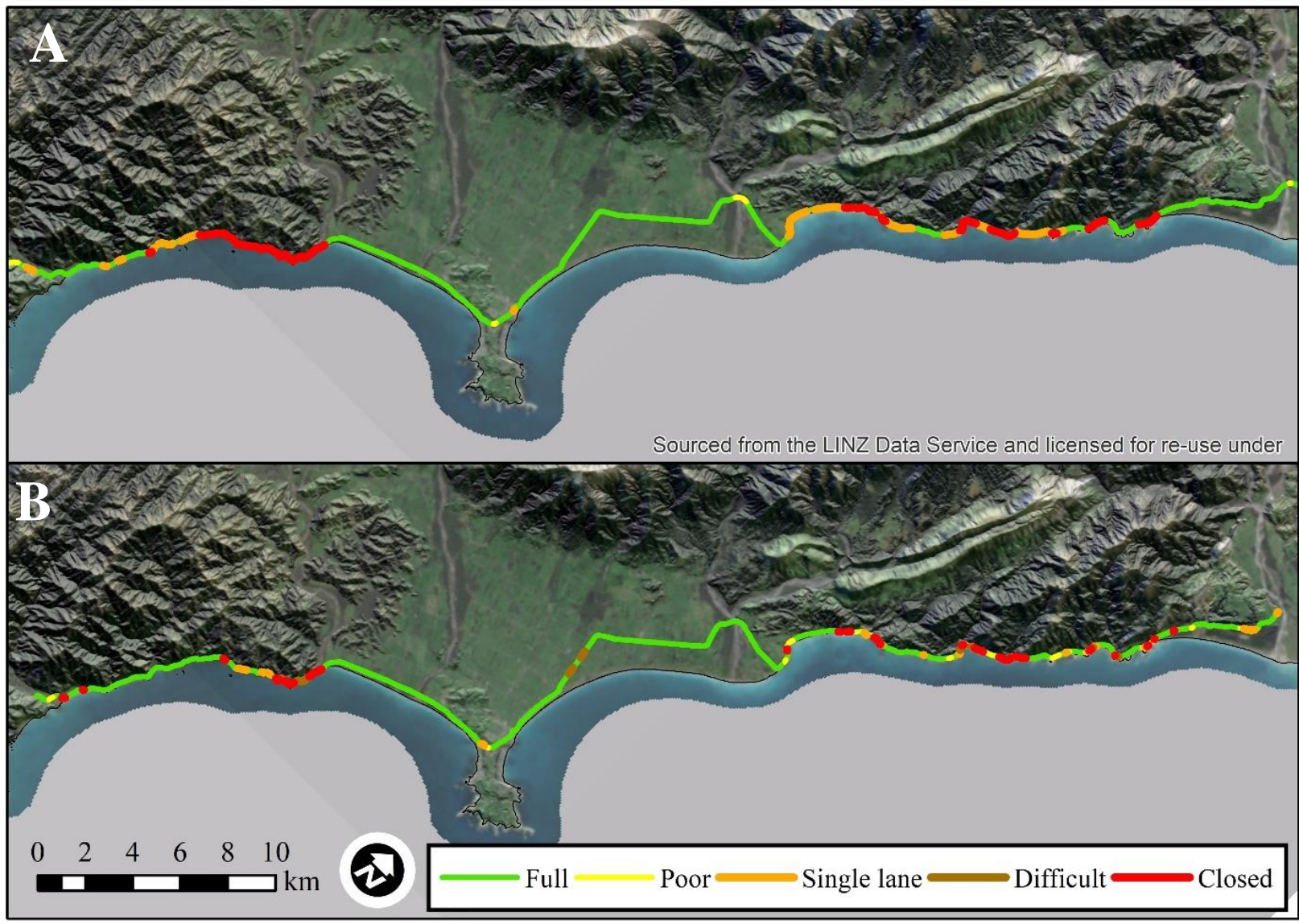

Figure 8: Comparison of the mapped resilience of the coastal section of State Highway 1 through Kaikoura with the actual performance of the corridor in the 2016 Kaikoura earthquake. (A) Assessed availability state for $\sim 1,000$ year RP earthquake [1]. (B) Observed road availability following the 2016 Kaikoura earthquake [24].

assessment. In other sections where vulnerable hillslopes were affected by landsliding, the full length of hillslope did not fail, with closure of the road only at discrete locations. Failure of the full length of hillslopes would not be expected in any one specific event.

There were some short sections of highway that were not identified as vulnerable to closure in the resilience assessment but were reduced to single lane or were closed in the 2016 earthquake. These were generally due to a greater runout from landslides and debris flows from gullies that were not recognised in the 2001 study. Similarly, fault rupture completely closed the road at a number of locations, but this type of earthquake-induced ground damage was not included in the 2001 assessment, as it was not based on specific fault rupture events.

Failure of un-engineered embankments and gravity retaining structures led to reduced road availability, as predicted by the 2001 study. However, fewer seawalls failed and led to lane closure in the earthquake than predicted. This may be due to a combination of lower levels of ground shaking in the earthquake than assumed in the 2001 assessment, and possibly better foundation conditions and less unfavourable earthquake ground shaking characteristics and orientation compared to the orientation of the walls in this particular earthquake.

\section{Outage Effects}

The outage at each individual location was dependent on the type and magnitude of damage. Failures on slopes with limited slope height ( $10 \mathrm{~m}$ to $40 \mathrm{~m}$ ) were able to be cleared more readily and the road reopened compared to failures on high hillsides extending $50 \mathrm{~m}$ to $100 \mathrm{~m}$ or more. Small landslides required clearance of small volumes of debris, on the order of tens to hundreds of cubic metres, which generally took a few days to weeks. Larger landslides, with many thousands to tens of thousands of cubic metres of debris, took weeks to many months to clear. This included time for field reconnaissance, planning, sluicing and abseil scaling to remove safety hazards, followed by earthmoving. Failures of embankments, retaining walls and sea walls also took many months to repair, to carry out ground investigations, design, and construction.

The outage state was not assessed in the 2001 study, but the potential for such prolonged outages associated with failure of embankments, retaining structures and high slopes was taken into consideration in the 2016 national study and can be compared to the actual outage from the earthquake. The 2016 study predicted long term (between 2 and 6 months) to very long term (greater than 6 months) closure following a large earthquake on the Kaikōura coast. The section of SH1 north of Kaikōura remained closed for 13 months, and was reopened for limited single lane access during daylight hours only for a further 4 months. The section of SH1 south of Kaikoura was opened to limited one lane access after six weeks [13], but was subsequently closed following further slope failures in rain storms in April 2017. Parts of the state highway corridor between Clarence River and Oaro remained single lane due to ongoing repairs and slope stabilisation and risk mitigation works until 2020. This demonstrates that restoration of access following an event occurs in stages rather than as a linear process from loss of service to full access as idealised in Figure 2. The outage state is therefore more useful to consider holistically on a corridor level, rather than at each individual location, as clearance or repair at any individual section does not necessarily provide access for the whole corridor. 
Overall, the resilience of the corridor assessed before the 2016 earthquake was largely realised in that event, with the route closed over most of the coastal section for a long period of time, confirming the value of resilience and vulnerability assessments to anticipate potential hazard impacts and enable planning of interventions and response to enhance resilience to hazard events.

\section{EARTHQUAKE RECOVERY}

The North Canterbury Transport Infrastructure Recovery (NCTIR) alliance was set up by the government under the Hurunui/Kaikōura Earthquakes Recovery Act 2016. NCTIR consisted of an alliance between NZTA, the asset owner for the state highways, KiwiRail, the asset owner for the railway, and New Zealand's four largest infrastructure contractors. Engineering consultants were engaged by the alliance to provide the technical capability to investigate, assess, develop and design the measures to restore functionality and enhance resilience. Specialist subcontractors were engaged for construction of the repair and mitigation works. NCTIR's immediate purpose was to repair and re-open the earthquakedamaged road and rail networks on the Kaikōura Coast and the inland road (Route 70) between Kaikōura and Waiau, and to repair and restore the harbour in Kaikōura. The asset owner outcome requirements for the NCTIR programme were to achieve an acceptable level of safety and service for day to day operations. Two key outcomes were developed as part of the NCTIR programme:

Risk to Life: Target risk levels were determined separately by both asset owners, with As Low As Reasonably Practicable (ALARP) principles applying for risks lower than these levels. The risk estimation for the state highway was completed using the New South Wales Roads and Maritime Services (NSW RMS) Guide to Slope Risk Analysis [25]. Slope risk adjacent to the rail corridor was assessed using KiwiRail's in-house slope hazard rating (SHR) system as a proxy.

Level of Service: KiwiRail and NZTA specified acceptable duration outages for different return periods, expressed as an Annual Recurrence Interval (ARI). The target outages ranged from a few hours for frequent events, to over 120 days' outage for events in excess of 100-year ARI.

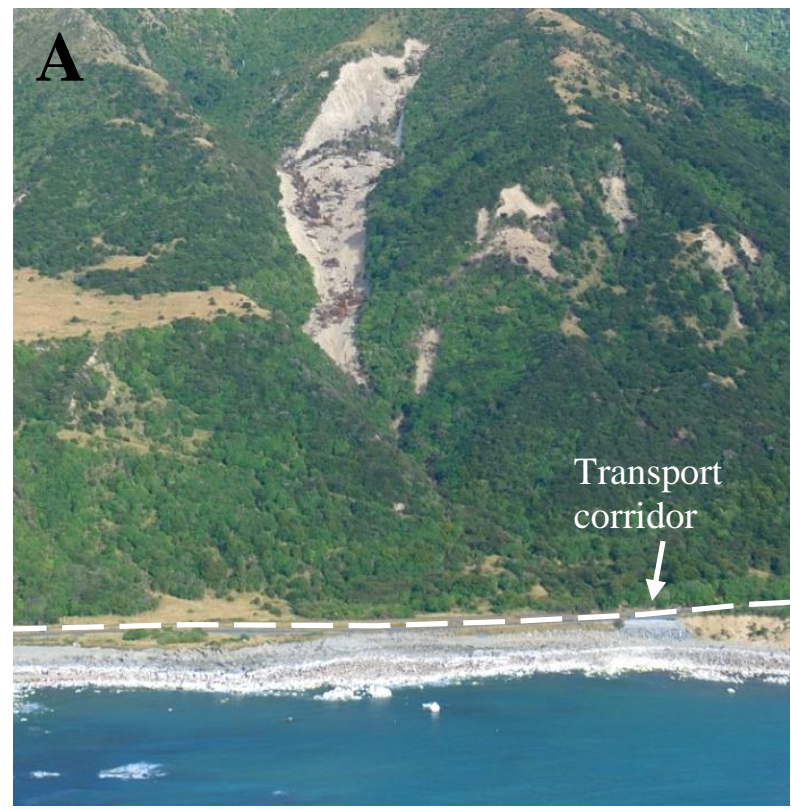

At any one site, mitigation work involved implementation of one or more solutions that addressed the two outcome areas above. In general, the mitigation solutions involved engineered stabilisation and protection works. However, non-engineered works, such as operational controls in response to earthquakes or rainfall, were also considered as part of the suite of mitigation measures. The mitigation measures and strategies for enhancing resilience are described in more detail in the discussion below.

\section{POST-EARTHQUAKE IMPACTS}

Slope failures (landslides and embankment failures) caused the most damage and disruption to the transportation infrastructure in the Kaikōura earthquake [26]. In addition to the areas where coseismic landslides resulted in damage to the transport corridor, many areas of hillside and ridge cracking occurred during the earthquake without causing landslides. In other areas, landslides were initiated but the debris was retained on the hillslopes or in gullies above the transport corridor. Following the earthquake, a number of failures developed in response to heavy rainstorms, including re-mobilisation of existing landslide debris fans into debris flows (Figure 9), and landslides or debris flows from slopes that had been cracked or damaged in the earthquake (Figure 10).

Overseas experience has shown that large earthquakes not only trigger extensive landsliding but also increase the number and intensity of subsequent rainfall-induced landslides [27,28]. Experience from the 1999 Chi-Chi earthquake in Taiwan and the 2008 Wenchuan earthquake in China shows that the critical rainfall thresholds for triggering landslides and debris flows decrease significantly following large earthquakes. The heightened landslide initiation probability persists for over a period of several years, with a gradual return to the preearthquake conditions $[29,30]$. In mountainous terrain, it can take significantly longer to return to pre-earthquake levels of landsliding [31,32].

In New Zealand, analysis of the distribution and characteristics of coseismic landslides triggered by the 1929 Murchison and 1968 Inangahua earthquakes identified hillslopes that did not fail in the 1929 earthquake but subsequently failed in the 1968 event as a result of the damage previously caused [33].

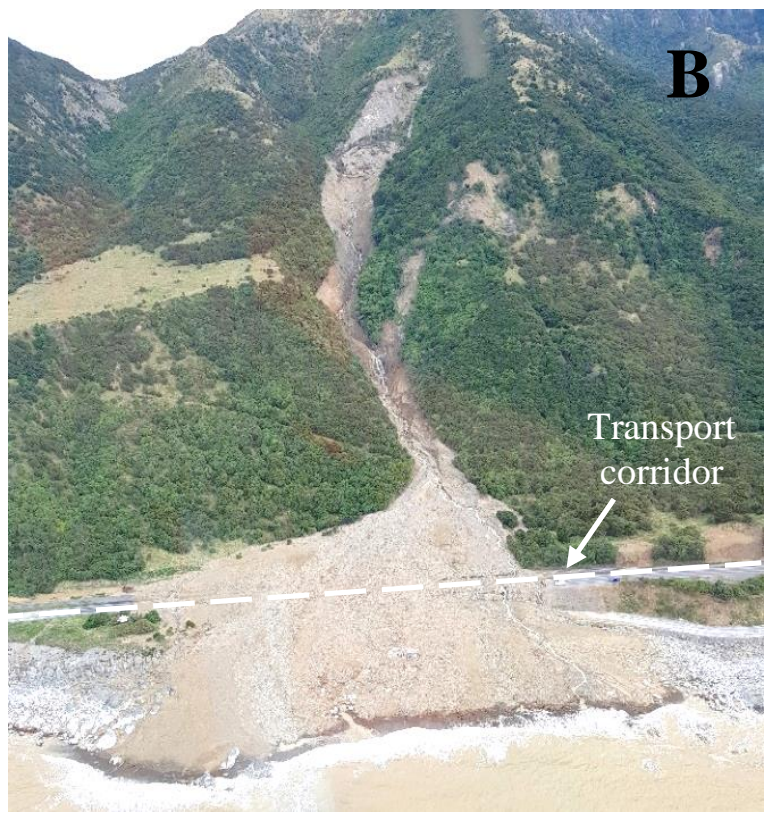

Figure 9: Examples of post-earthquake debris flow at Jacobs Ladder, north of Kaikoura (locations are shown in Figure 6). (A) Debris fan from earthquake-induced landslide retained in a gully above the transport corridor (January 2017). (B) Complete burial of the transport corridor by debris flows triggered during ex-Tropical Cyclone Gita (February 2018). 



Figure 10: Examples of post-earthquake slope failure at Rosy Morn, south of Kaikoura. (A) Photo of the earthquake-induced landslide at Rosy Morn (February 2017). The adjacent slope (dashed line) did not fail in the earthquake. (B) Failure of the hillslope adjacent to the Rosy Morn landslide as a result of heavy rainfall during ex-cyclones Debbie and Cook in April 2017 and Gita in February 2018.

These examples from New Zealand and overseas show that the consequential 'slope weakening' effect of strong ground shaking in hilly terrain can persist in the landscape for many years to decades. The rates of slope failures along the Kaikōura coastal transport corridor are therefore expected to be significantly elevated for a period of many years to decades following the earthquake, and consequently the post-earthquake resilience of the corridor is significantly reduced compared to its pre-earthquake condition. This highlights the need to understand the earthquake performance of natural hillslopes, cut slopes and fill slopes along transport corridors, both for the design of resilient infrastructure and the management of hazards along existing infrastructure corridors.

\section{ASSESSMENT OF FUTURE RESILIENCE}

Recognising this increased vulnerability, the future resilience of the coastal transport corridor was assessed by NCTIR against the level of service targets set by the road and rail asset owners [34]. The resilience assessment was focused on the expected performance of slopes, based on observations of slope behaviour following the Kaikoura earthquake along with the evidence from New Zealand and overseas. The objective was to identify sections of the corridor that were prone to future slope failures and were priorities for engineering works that would help enhance or restore resilience. This work involved systematic assessment of the vulnerability of the slopes along the rail and road corridors between Oaro and Clarence River, incorporating the NCTIR geotechnical team's assessment of landslide areas, supplemented by geomorphological assessment of the slopes which did not fail in the earthquake but which were damaged by ground shaking and are subsequently more susceptible to failure due to rainfall. The assessment considered the slope failure history, the types of anticipated slope failures and the consequent impacts on the transport corridor, observations of the time taken to clear debris, and the requirements or logistics for repair and reinstatement. The type and extent of any planned or completed engineered works were also considered.

The assessment of future resilience included estimation of outages of the transport corridor for given hazard events. This was carried out for a range of potential trigger events (consisting of small to large storm and earthquake events) and several time periods, being target dates for reopening of the rail and road corridors as well as a nominal end date for the NCTIR programme. This helped identify the potential improvement in resilience required from the completion of engineering works and reduction in aftershock hazard, but also identify if resilience will significantly decrease following the completion of the
NCTIR programme of works given the consequent reduction in availability of plant and personnel to respond quickly to slips or other outages.

The resilience assessment showed that significant clusters of potential long duration outage could occur at the steep hillside sections along the coastal corridor, particularly around the areas of heavy damage from the Kaikōura earthquake (e.g. Figure 11).

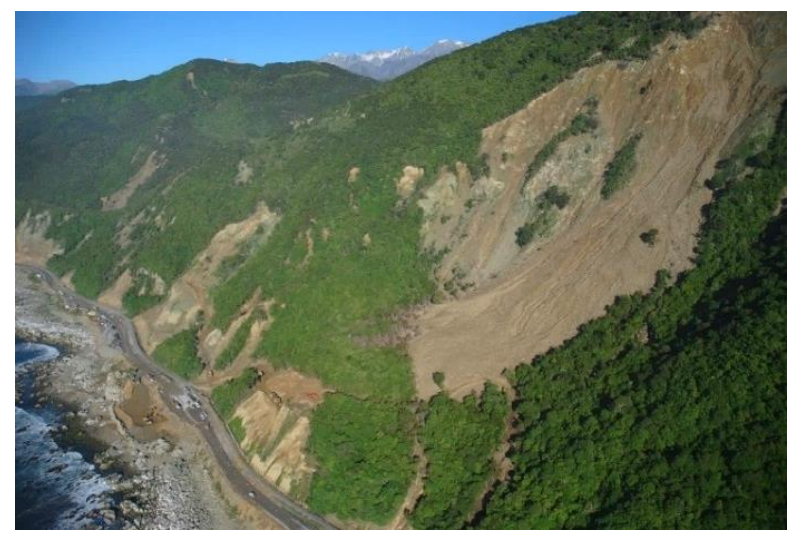

Figure 11: Examples of earthquake-damaged hillslopes in Half Moon Bay, north of Kaikoura, assessed as highly vulnerable to future failure in earthquake or rainfall events (see Figure 6 for location).

Figure 12 shows an extract from the resilience assessment, showing the outage resulting from the 2016 earthquake as well as the assessed potential outages along a section of the road corridor north of Kaikoura. These sections of corridor were assessed as highly vulnerable to further earthquake- or rainfalltriggered failure due to the fractured and disrupted nature of the rock mass underlying the slope and the presence of large volumes of landslide debris and colluvium on the slopes, as well as extensive areas of tension cracking and slope deformation. These slopes show a range of behaviours depending on the size and type of the hazard scenario, from small-scale slips and debris flows under relatively small, high frequency rainfall events to large landslides and debris avalanches/flows in severe storms or large earthquakes. This understanding of the vulnerabilities along the corridor enabled the asset owners to identify and prioritise critical sections of the corridor for engineering works to enhance resilience and to develop response measures for future events to minimise the impact of outages in those critical sections. 


\section{STRATEGIES FOR RESILIENCE ENHANCEMENT IN RECOVERY OPERATIONS}

As described above, resilience may be defined as the ability of the asset to recover quickly and return to original form following an adverse event. Metrics to assess the resilience of transport infrastructure include the 'availability state', which defines the level of access after the event (representing the reduced level of service), and the 'outage state', which represents the duration of reduced access at a given availability state [2]. Hughes and Healy [35] provide an expanded definition of resilience, with two categories each with three aspects; the cumulative total of which provide the total resilience:

- Technical aspects

$$
\begin{array}{ll}
\circ & \text { Robustness } \\
\circ & \text { Redundancy } \\
\circ & \text { Safe-to-fail (design performance) }
\end{array}
$$

- Organisational aspects
- Change readiness (response)
- Networks (response)
- Leadership and culture

Of these, the NCTIR resilience assessment focused on the following elements:
- Robustness - this reflects the strength or ability of assets to withstand a level of stress without suffering degradation or loss of function;

- Redundancy - this considers the extent to which assets or networks are substitutable, i.e. capable of satisfying functional requirements in the event of disruption, degradation, or loss of functionality. An example of this would be the use of an alternative route (either locally or regionally) in the case of damage to the primary route;

- Response - this includes the ability to sense and anticipate hazards, develop a forewarning of disruption threats, and have the ability to respond quickly if a particular hazard occurs.

Initiatives that strengthen each of these aspects will therefore contribute to overall improvement of the resilience. At any one site, repair and mitigation work involved implementation of solutions to achieve the life safety and level of service targets required by KiwiRail and NZTA. In general, the mitigation solutions involved engineered stabilisation and protection works. However, non-engineered works, such as operational controls in response to earthquakes or rainfall, were also implemented on a corridor-wide basis for operation during the NCTIR recovery works. The specific measures implemented for each of these aspects are discussed below.

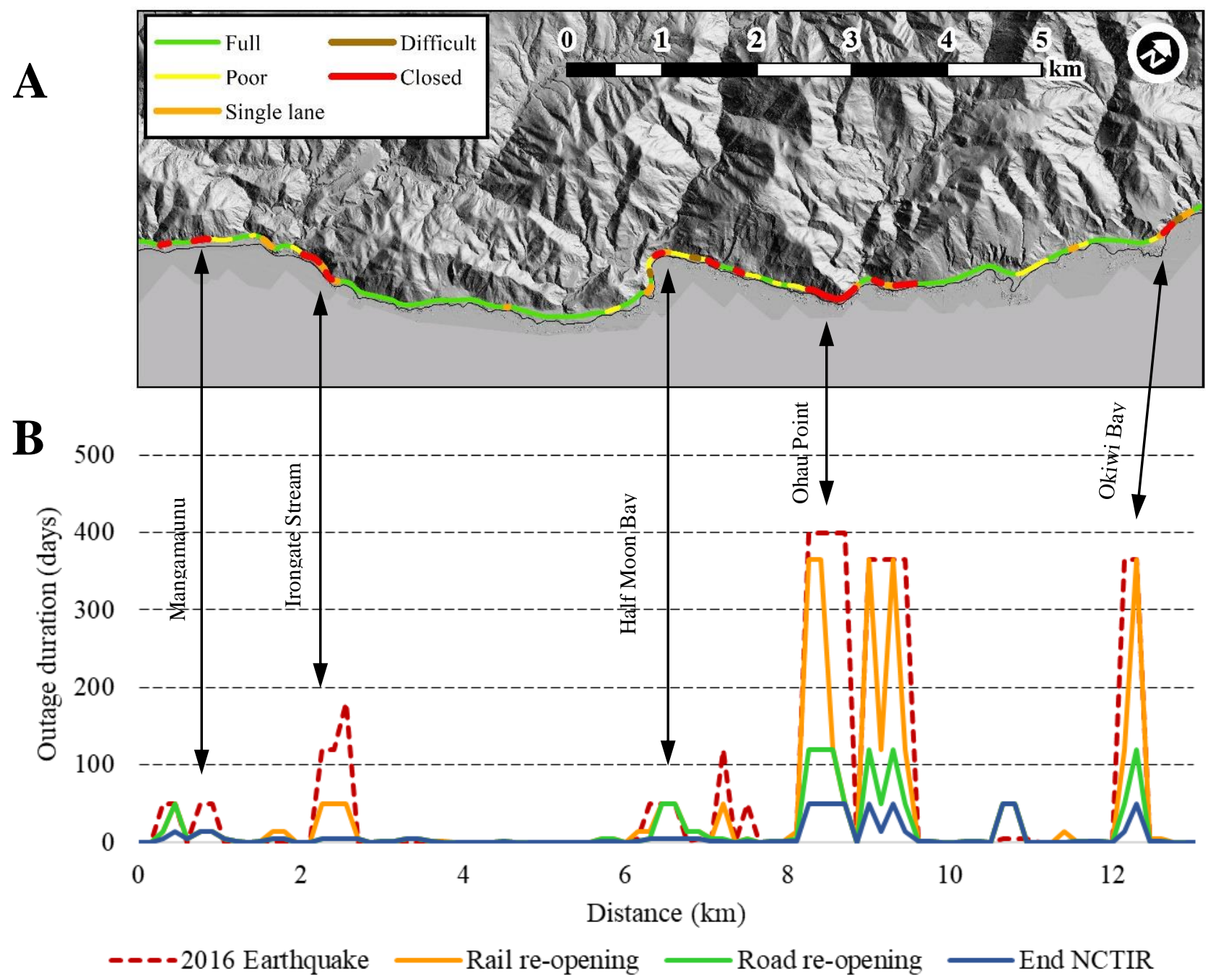

Figure 12: Extract from resilience assessment for SH1. (A) Map of the loss of SH1 availability in the 2016 earthquake between Mangamaunu and Okiwi Bay (see Figure 6 for location). (B) Graphical representation of individual site outages from the earthquake, and potential outages for a large magnitude earthquake (MM VII+) at the re-opening of the rail and road corridors and at the nominal end date for the NCTIR programme. 


\section{Robustness}

Strategies to strengthen the robustness of road and rail assets help reduce the potential for a loss of service after a significant hazard event. Measures to improve the robustness of the corridor included realigning the road and rail away from the steep hillsides, engineered works to reduce the potential for slope failure, and engineered works to reduce the potential for inundation of the corridor. Engineered risk mitigation solutions can be considered as either reducing the likelihood (active mitigation) or consequence of failure (passive). Active solutions typically included:

- Scaling, boulder removal and sluicing;

- Bulk earthworks to re-profile slopes at risk of further failure (Figure 13A);

- Slope stabilisation with rock bolts and mesh;

- Anchored rock fall netting (Figure 13B);

- Installation of drainage measures to relieve groundwater pressures or control surface water runoff.
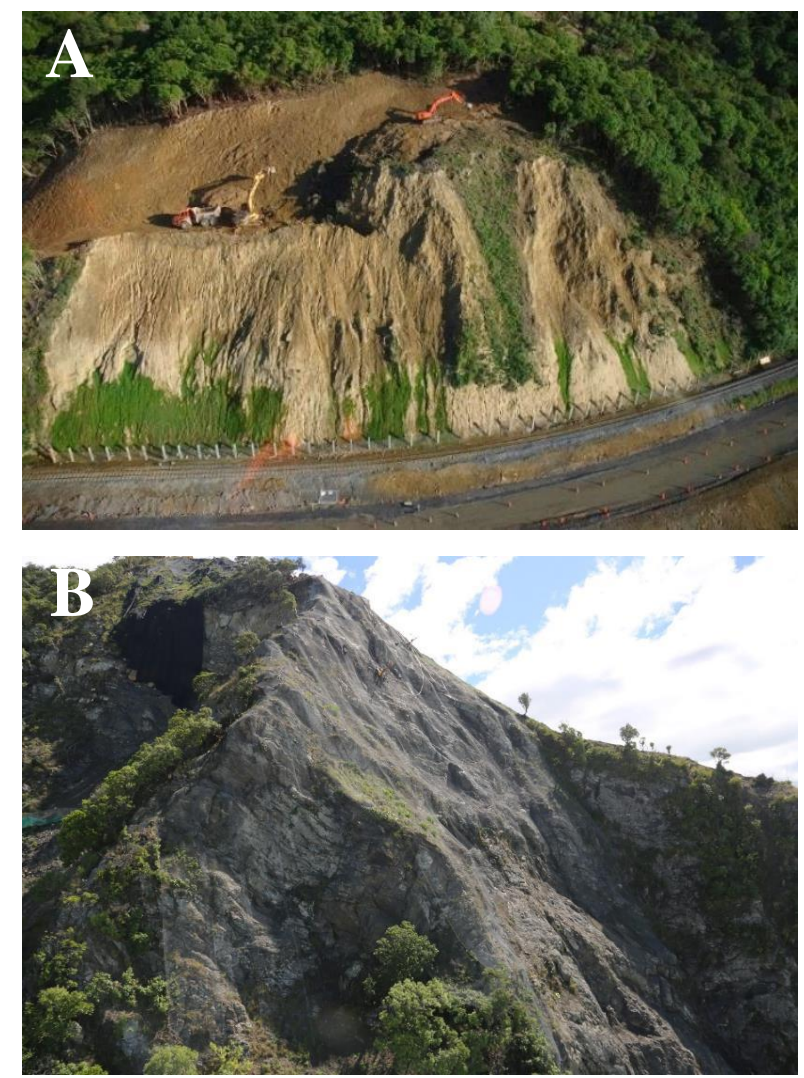

Figure 13: Examples of active mitigation solutions implemented by NCTIR (see Figure 6 for locations). (A) Slope re-profiling and bulk earthworks at one of the major landslide sites in Half Moon Bay, north of Kaikoura. (B) Rock anchors and mesh stabilisation of a fractured and disturbed rock slope above SHI at the Parititahi Tunnels, south of Kaikōura.

Passive mitigation measures included:

- Remote monitoring, such as tripwire fences, extensometers, and GPS sensors;

- Rock fall and debris catch fences/attenuators (Figure 14A);

- Shallow landslide barriers;

- Earth bunds and hybrid bunds/fences;

- Catch-ditch earthworks;
- Rock fall and debris avalanche shelters;

- Construction of new bridges to allow debris flows to pass beneath the transport corridor;

- Seaward realignment of the rail and road corridors away from the hazardous hillslopes (Figure 14B).
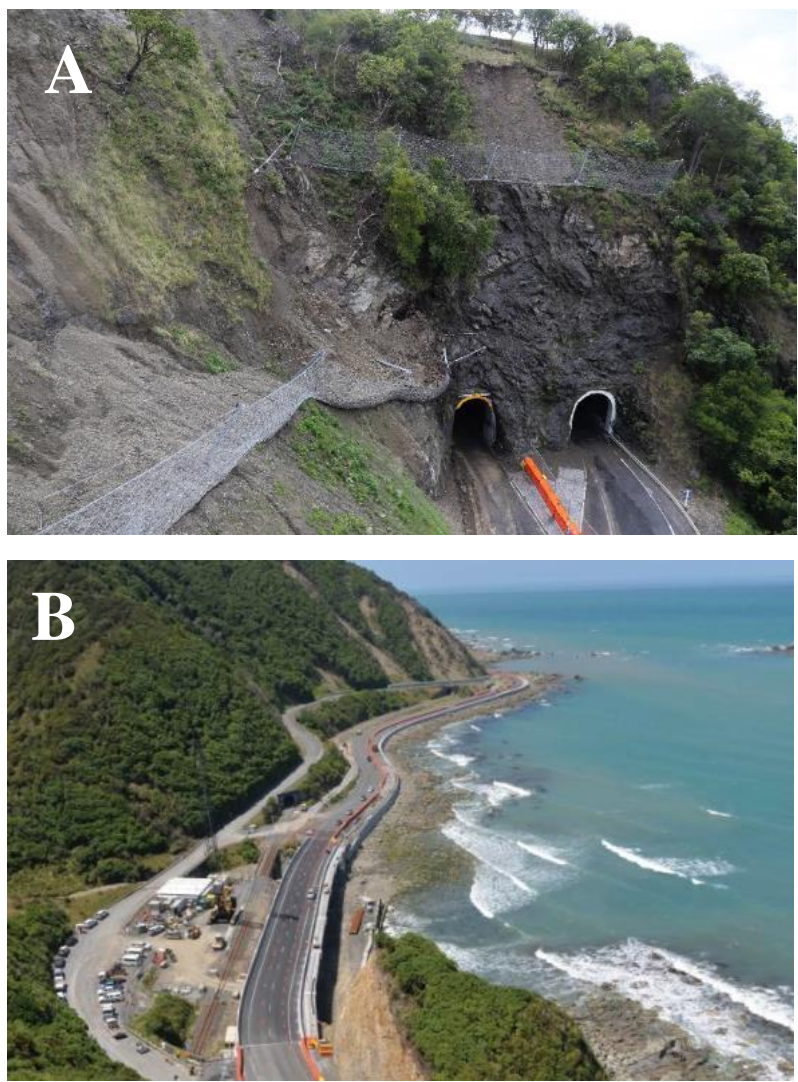

Figure 14: Examples of passive mitigation solutions implemented by NCTIR (see Figure 6 for locations). (A) Rock fall/debris catch fences protecting SH1 at the Raramai Tunnel portals, south of Kaikoura. (B) Realignment of the state highway onto the uplifted shore platform away from the hillslopes at Irongate Stream, north of Kaikōura.

\section{Redundancy}

Planning new alternative routes or enhancing the resilience of existing alternative routes to the existing vulnerable transportation links improves resilience through enhancing redundancy within the network. There are few options to improve redundancy for the rail as the MNL is the sole rail route between Canterbury and Marlborough. For the road network, redundancy was enhanced by repairing and upgrading the inland Route 70 between Waiau and Kaikōura and strengthening key vulnerabilities on the alternative NelsonMarlborough and Lewis Pass state highway route between Blenheim and Waipara (SH63-SH6-SH65-SH7). These routes are shown on Figure 1.

\section{Response}

Emergency response preparedness reduces the outage period and helps bring the transport link back into normal service quickly. The NCTIR alliance provided KiwiRail and NZTA with the ability to react quickly in the event of a hazard event with a large contingent of plant and personnel based in Kaikōura. Establishment of temporary weather stations throughout the NCTIR works area enabled data to be collected on the depth, intensity and spatial variation of rainfall events along the corridor. Observations of post-earthquake slope 
failures by NCTIR geologists and construction personnel were instrumental in understanding the frequency and magnitude of slope failures in response to these rainfall events. This was fundamental to the development of operational measures to ensure safety of construction personnel while allowing the recovery operations to proceed in the context of enhanced risk associated with storm events and potential aftershocks.

Rainfall Trigger Action Response Plans (TARPs) were developed for the road and rail corridors, with probabilistic thresholds established based on rainfall-slope failure relationships that were determined for the Kaikōura area from the records of slope failures following the earthquake [36]. Based on forecast rainfall, the TARPs enabled assessment of potential slope risks for construction activities, freight trains, and public traffic on $\mathrm{SH} 1$, hence predicting when pre-emptive route closures may be needed for safety reasons.

The following measures were taken to enhance organisational response for management and maintenance of the network after the NCTIR recovery works are completed:

- Installation of tripwire fences with remote monitoring sensors to notify when rock falls or slips occur;

- Monitoring of unstable slopes with GPS sensors and ground surveys to provide a forewarning of slope failure;

- Rainfall Trigger Action Response Plans (TARPs);

- Monitoring the changes in safety and resilience risks using recorded rock fall and landslide events;

- Implementation of streamlined response plans for hazard events, such that personnel and plant can be mobilised quickly in the event of failure.

The corridor resilience could be further developed following the completion of the NCTIR recovery programme by development of an integrated, network level asset management strategy for the transport corridor. This would allow asset management and resilience enhancement to be considered in an integrated manner alongside maintenance, safety improvements and capacity improvements.

\section{RESEARCH AND FUTURE PRACTICE}

Further understanding of the earthquake effects of the Kaikoura earthquake and its effect on the landscape, landslide runout and debris cascade mechanisms and the performance of earthworks will help understand the resilience of transport corridors including the Kaikoura corridor to earthquakes and storms in future hazard events, and enhance our resilience assessment, design and management measures. A current 5-year research funded under the Endeavour Programme will lead to a better understanding of the potential failure mechanisms and impacts. This will help develop improved approaches to design and risk management practice. In addition, a resilience-based design approach would be prudent to ensure that resilience is a key focus in our future design practice [37].

\section{CONCLUSIONS}

Experience from the November 2016 Kaikōura earthquake shows the need to understand the resilience of existing infrastructure in earthquakes. The earthquake caused widespread damage and severe disruption to the road and rail networks across the northeast of the South Island. State Highway 1 through Kaikoura was closed for 13 months and the rail corridor for 9 months due to earthquake-induced slope failures and other failures of embankments and damage to bridges and tunnels. Assessments of the resilience of the State Highway 1 corridor to potential earthquakes made before the 2016 earthquake were largely realised in that event, confirming the value of resilience assessments to anticipate potential natural hazard effects and enable planning of interventions and response to enhance resilience to hazard events.

An alliance of road and rail asset owners and contractors was formed after the earthquake and was supported by a range of engineering consultants, which helped develop and implement a programme of engineered and non-engineered recovery works to reopen the road and rail network. Post-earthquake landslides and debris flows in rain events showed the earthquake-damaged slopes are much more vulnerable to future failures, and experience from overseas shows this condition will likely persist for years to decades. The post-earthquake resilience of the transport corridor to future storm and earthquake events was assessed to help quantify the increased vulnerability of the corridor. This assessment enabled development of strategies to enhance resilience as part of the recovery works. This included engineered measures to strengthen the corridor to reduce the potential loss of service, monitoring and response plans to improve response and recovery time, and operational controls to allow proactive management of the safety risks along the corridor for construction activities and public traffic.

The long outage of this nationally important transportation corridor highlights the need for prior planning to understand the resilience of our infrastructure, identify resilience gaps and to plan for event response and/or invest in strengthening key vulnerabilities. It also highlights the need to improve our understanding of the seismic performance of infrastructure such as cut slopes, fill embankments and retaining systems, as well as the wider effects of large earthquakes on landslide triggering, runout and debris cascade mechanisms in the regional landscape. This will lead to a better understanding of the potential failure mechanisms and impacts, which will help develop improved approaches to design and resilience management practice.

\section{ACKNOWLEDGMENTS}

The authors are thankful to the NZ Transport Agency, KiwiRail and NCTIR for providing data for this paper, and the team of geologists and engineers who were involved in the immediate emergency response and subsequent NCTIR recovery project. We also wish to acknowledge the NZ Transport Agency and KiwiRail's involvement and commitment to natural hazard risk management and resilience planning. Comments from the reviewers helped improve the paper. Support of WSP in the preparation of this paper is also gratefully acknowledged.

\section{REFERENCES}

1 Brabhaharan P, Fleming M and Lynch R (2001). "Natural Hazard Risk Management for Road Networks. Part I: Risk Management Strategies". Transfund New Zealand Research Report 217, Opus International Consultants, Wellington, NZ, 75pp.

2 Brabhaharan P, Wiles L and Freitag S (2006). "Natural Hazard Risk Management for Road Networks. Part III: Performance Criteria". Land Transport New Zealand Research Report 296, Opus International Consultants, Wellington, NZ, 117pp.

3 Mason D and Brabhaharan P (2017). "Resilience assessment of state highways in New Zealand". Proceedings of the Annual Conference of the New Zealand Society for Earthquake Engineering, 27-29 April, Wellington, NZ, Paper No O2C.2, 8pp.

4 James A (2016). "SHI Picton to Christchurch (Ashley River Bridge) Strategic Case". NZ Transport Agency, Christchurch, NZ, 33pp. 
5 Bell D (1976). "High intensity rainstorms and geological hazards: Cyclone Alison, March 1975, Kaikōura, New Zealand". Bulletin of the International Association of Engineering Geology, 14: 189-200.

https://doi.org/10.1007/BF02634795

6 Clydesdale J (2000). "The Economic Impact of Road Closures Caused by Natural Hazards - Case Study Kaikōura". Masters Thesis, Lincoln University, Lincoln, NZ, 133pp.

7 Beca Infrastructure Ltd (2010). "SH 1 Blenheim to Ashley River Bridge Strategy 2010-2040”. NZ Transport Agency, Christchurch, NZ, 145pp.

8 Brabhaharan P (2004). "Systematic management of the risks to transportation networks from natural hazards". 2nd International Symposium on Transportation Network Reliability, 20-24 August, Christchurch, NZ.

9 Speed J and Brabhaharan P (2006). "Western Bay of Plenty road network risk assessment". Proceedings of the New Zealand Geotechnical Society Symposium on "Earthquakes and Urban Development", 17-18 February, Nelson, NZ.

10 Brabhaharan P (2010). "Integrated resilience of transportation lifelines in the Wellington region". Proceedings of the Annual Conference of the New Zealand Society for Earthquake Engineering, 26-28 March, Wellington, NZ.

11 Mason D and Brabhaharan P (2013). "Resilience of transportation lifelines in the greater Wellington area". Proceedings of the $19^{\text {th }}$ New Zealand Geotechnical Society Symposium, 21-22 November, Queenstown, NZ, 8pp.

12 Brabhaharan P (2006). "Recent advances in improving the resilience of road networks remembering Napier 1931 Building on 75 years of earthquake engineering in New Zealand". Proceedings of the Annual Conference of the New Zealand Society for Earthquake Engineering, 10-12 March, Napier, NZ.

13 Davies A, Sadashiva V, Aghababaei M, Barnhill D, Costello S, Fanslow B, Headifen D, Hughes M, Kotze R, Mackie J, Ranjitkar P, Thompson J, Troitino D, Wilson T, Woods S and Wotherspoon L (2017). "Transport infrastructure performance and management in the South Island of New Zealand, during the first 100 days following the $2016 \mathrm{M}_{\mathrm{w}} 7.8$ "Kaikōura" earthquake". Bulletin of the New Zealand Society for Earthquake Engineering, 50(2): 271-299. https://doi.org/10.5459/bnzsee.50.2.271-299

14 Aghababaei M, Costello S and Ranjitkar P (2020). "Assessing operational performance of New Zealand's South Island road network after the 2016 Kaikōura earthquake". International Journal of Disaster Risk Reduction, 47: 101553, 10pp. https://doi.org/10.1016/j.ijdrr.2020.101553

15 Stirling M, Litchfield N, Villamor P, Van Dissen R, Nicol A et al. (2017). "The $M_{w} 7.82016$ Kaikōura earthquake: Surface fault rupture and seismic hazard context". Bulletin of the New Zealand Society for Earthquake Engineering, 50(2): 73-84. https://doi.org/10.5459/bnzsee.50.2.73-84

16 GNS Science (2020). Active Faults Database - Kaiköura 2016 Rupture. https://data.gns.cri.nz/af/ (Accessed 20/8/2020)

17 Kaiser A, Balfour N, Fry B, Holden C, Litchfield N et al. (2017). "The 2016 Kaikōura, New Zealand, earthquake: Preliminary seismological report". Seismological Research Letters, 88(3): 727-739. https://doi.org/10.1785/0220170018
18 Bradley B, Wotherspoon L and Kaiser A (2017). "Ground motion and site effect observations in the Wellington region from the 2016 Kaikōura, New Zealand earthquake". Bulletin of the New Zealand Society for Earthquake Engineering, 50(2): 94-105. https://doi.org/10.5459/bnzsee.50.2.94-105

19 GNS Science (2017a). Kaikoura quake produced strongest ground shaking in NZ, new research shows - 10/04/2017. https://www.gns.cri.nz/Home/News-and-Events/Media-

Releases/strongest-ground-shaking-in-NZ

(Accessed 11/04/2017)

20 GNS Science (2017b). Geonet. http://shakemap.geonet.org.nz/mapping/2016p858000.htm 1 (Accessed 11/04/2017)

21 Mason D and Brabhaharan P (2019). "Resilience of transport corridors in the 2016 Kaikoura earthquake, to inform recovery and future slope design and landslide hazard management". Proceedings of the $2^{\text {nd }}$ International Conference on Natural Hazards and Infrastructure, 23-26 June, Chania, Greece, Paper No 997, 12pp.

22 Mason D, Brabhaharan P and Fenton C (2021). "Characteristics and impacts of landslides along transport routes in the 2016 Kaikōura earthquake, New Zealand". Manuscript in preparation.

23 NCTIR (2017). "Kaikōura Earthquake Update 30 January 2017". https://www.nzta.govt.nz/assets/projects/northcanterbury-transport-infrastructure-recovery/Kaikouraearthquake-update-20170130.pdf (Accessed 20/7/2020)

24 Brabhaharan P, Mason D and Callosa-Tarr J (2017). "Resilience of State Highways. Lessons from the 2016 Kaikōura Earthquake for Resilience Studies". Client Report GER2017-29, Opus International Consultants, Wellington, NZ, 53pp.

25 New South Wales Roads and Maritime Services (2014). "Guide to Slope Risk Analysis. Version 4, April 2014". NSW Government, North Sydney, Australia, 135pp.

26 Mason D, Brabhaharan P and Saul G (2017). "Performance of road networks in the 2016 Kaikoura earthquake: observations on ground damage and outage effects". Proceedings of the 20th NZGS Geotechnical Symposium, 24-26 November, Napier, NZ, 8pp.

27 Lin C-W, Liu S-H, Lee S-Y and Liu C-C (2006). "Impacts of the Chi-Chi earthquake on subsequent rainfall-induced landslides in central Taiwan". Engineering Geology, 86: 87-101. https://doi.org/10.1016/j.enggeo.2006.02.010

28 Zhang S, Zhang LM and Glade T (2014). "Characteristics of earthquake- and rain-induced landslides near the epicenter of Wenchuan earthquake". Engineering Geology, 175: 58-73. https://doi.org/10.1016/j.enggeo.2014.03.012

29 Chen JC, Jan CD and Huang WS (2013). "Characteristics of rainfall triggering of debris flows in the Chenyulan watershed, Taiwan". Natural Hazards and Earth System Sciences, 13: 1015-1023. https://doi.org/10.5194/nhess-13-1015-2013

30 Hovius N, Meunier P, Lin C-W, Chen H, Chen Y-G, Dadson S, Horng M-J and Lines M (2011). "Prolonged seismically induced erosion and the mass balance of a large earthquake". Earth and Planetary Science Letters, 304: 347-355. https://doi.org/10.1016/j.eps1.2011.02.005

31 Li L, Yao X, Zhang Y, Iqbal J, Chen J and Zhou N (2016). "Surface recovery of landslides triggered by 2008 Ms8.0 Wenchuan earthquake (China): A case study in a typical mountainous watershed". Landslides, 13: 787-794. https://doi.org/10.1007/s10346-015-0594-1 
32 Tang C, Van Westen CJ, Tanyas H and Jetten VG (2016). "Analysing post-earthquake landslide activity using multitemporal landslide inventories near the epicentral area of the 2008 Wenchuan earthquake". Natural Hazards and Earth System Sciences, 16: 2641-2655. https://doi.org/10.5194/nhess-16-2641-2016

33 Parker R, Hancox G, Petley D, Massey C, Densmore A and Rosser N (2015). "Spatial distributions of earthquakeinduced landslides and hillslope preconditioning in the northwest South Island, New Zealand". Earth Surface Dynamics, 3: 501-525. https://doi.org/10.5194/esurf-3-501-2015

34 Mason D, Justice R and McMorran T (2018). “Assessment of the resilience of the north Canterbury transport network following the 2016 Kaikoura earthquake". Proceedings of the 2018 IPWEA New Zealand Conference, 20-22 June, Rotorua, NZ, Paper No 507a, 8pp.
35 Hughes J and Healy K (2014). "Measuring the Resilience of Transport Infrastructure". NZ Transport Agency Research Report 546, 82pp.

36 Justice R, Saul G and Mason D (2018). "Kaikōura earthquake slope hazards - risk mitigation and network resilience". NZ Geomechanics News, 96: 26-37.

37 Brabhaharan P (2018). "Evolution of resilience-based design of infrastructure". 17th US-Japan-New Zealand Workshop on the Improvement of Structural Engineering and Resilience, 14 November, Queenstown, NZ. 